\title{
EXPORTAÇÃO DE SERVIÇO, UMA OPORTUNIDADE PARA O CRESCIMENTO E A INTERNACIONALIZAÇÃO
}

\author{
R.A.S. Alexandre ${ }^{1, *}$; D. Soares ${ }^{1}$; R.F. dos Santos $^{1}$ \\ 1 Faculdade de Tecnologia de São José dos Campos - Professor Jessen Vidal \\ Av. Cesare Mansueto Giulio Lattes, 1350 - Eugênio de Melo, São José dos Campos/SP, \\ CEP.: 12247-014, Brasil. \\ Telefone: (12) 3905-2423 \\ *raquelalexandre37@gmail.com
}

\begin{abstract}
RESUMO: A exportação de serviços é uma oportunidade para projetar empresas nacionais no mercado internacional, alavancando o faturamento e promovendo crescimento. O objetivo deste trabalho é analisar o mercado exportador de serviços da Região Metropolitana do Vale do Paraíba (RM Vale), identificando as áreas de concentração das empresas exportadoras e as possíveis razões desse agrupamento. Após ampla revisão bibliográfica e coleta de dados na base do MDIC-SISCOSERV, levantou-se um total de 232 empresas exportadoras em 7 cidades da RM Vale, compreendidas entre Jacareí e Guaratinguetá. A ferramenta mapa de calor do Excel apontou a cidade que concentra mais empresas exportadoras na região. Complementando o mapa de calor, analisou-se as alíquotas de imposto sobre serviço (ISS) aplicado em cada cidade, comparando esse fator com seus volumes exportados e concentração de empresas. Futuros trabalhos poderão analisar outras regiões para novas oportunidades de expansão e evolução da vocação pouco explorada de exportadores de serviço.
\end{abstract}

PALAVRAS-CHAVE: exportadoras; oportunidade; exportação de serviço; mercado internacional.

ABSTRACT: The export of services is an opportunity to launch national companies into the international market, with consequent leverage of revenues and growth. The objective of this work is to analyze the export market of services of the Região Metropolitana do Vale do Paraíba (RM Vale), to identify the areas of concentration of exporting companies and the possible reasons for this concentration. After extensive bibliographic review and data collection at the MDIC-SISCOSERV database, a total of 232 exporting companies were surveyed in 7 cities of RM Vale, between Jacareí and Guaratinguetá. The Excel's tool named heatmap, indicated the city with the largest concentration of export companies in the region. Complementing the heatmap, it was analyzed the tax rates on service (ISS) applied in each city, comparing this factor with its exported volumes and concentration of companies. Future works may analyze other regions for new opportunities for expansion and evolution of the unexplored vocation of service exporters.

KEYWORDS: exporting companies; opportunity; services export, international market.

\section{INTRODUÇÃO}

Este Artigo trata da exportação de serviços realizada por empresas situadas na RM Vale, aponta as cidades onde estão concentradas essas empresas e seus respectivos volumes movimentados. Adicionalmente, a pesquisa procura identificar os possíveis motivos que levaram a esta concentração em determinada cidade em detrimento de outras. 


\subsection{Problema em Estudo}

Entende-se por exportação de serviço a produção, venda e entrega de um produto intangível entre produtor e consumidor, pessoa física ou jurídica, residentes ou domiciliadas em países distintos. (SEBRAE, 2016)

Como exemplificação de exportação de serviço pode-se citar as seguintes situações: serviços de corretagem de ações, serviços educacionais, serviços bancários, serviços advocatícios e serviços de consultoria.

Em relatório do MDIC (2017), o setor de serviços no Brasil mostra índices semelhantes aos de países desenvolvidos. Em 2016 o setor terciário respondeu por $73 \%$ do PIB brasileiro, mostrando que este setor é peça fundamental na economia do país [...] o comércio de serviços tem demonstrado maior resiliência do que o comércio de mercadorias nos últimos anos, e que apesar da queda apresentada nas exportações em geral, o setor de serviços teve queda inferior ao do setor de bens.

Com base em dados do BCB (2016), observa-se um espaço relevante para a expansão das exportações de serviços no Brasil.

\subsection{Relevância do Tema}

Este estudo visa evidenciar as principais questões e o avanço alcançado nos últimos anos no setor de exportação de serviços. Para isso será feita uma coleta e análise de dados, que, em um primeiro momento será dimensionada a importância do setor e a posição do Vale do Paraíba nesse contexto.

Segundo Guia do MDIC (2017) esse tipo de levantamento pode ser uma fonte de consulta para a formulação de futuras políticas de exportação de serviços.

\subsection{Objetivos}

Este Artigo tem como objetivo geral analisar o mercado exportador de serviços na Região Metropolitana do Vale do Paraíba (RM Vale), identificando as áreas de concentração das empresas exportadoras e as razões para essa concentração. Para atingir este objetivo foram estabelecidos os seguintes objetivos específicos:

a) desenvolver pesquisa bibliográfica a respeito das operações de exportação de serviços realizadas por empresas do Vale do Paraíba no ano 2016;

b) coletar dados;

c) aplicar o mapa de calor para classificar as regiões de concentração dessas empresas no Vale do Paraíba;

d) desenvolver estudo de caso; e cidade.

e) identificar os motivos para a concentração de empresas exportadoras em uma determinada

\subsection{Proposta Metodológica}

Para atender os objetivos deste trabalho, a metodologia de pesquisa utilizada foi baseada nos quatro pilares: quanto à natureza, à abordagem, aos objetivos e aos procedimentos técnicos, conforme especificado na Figura 1 a seguir: 


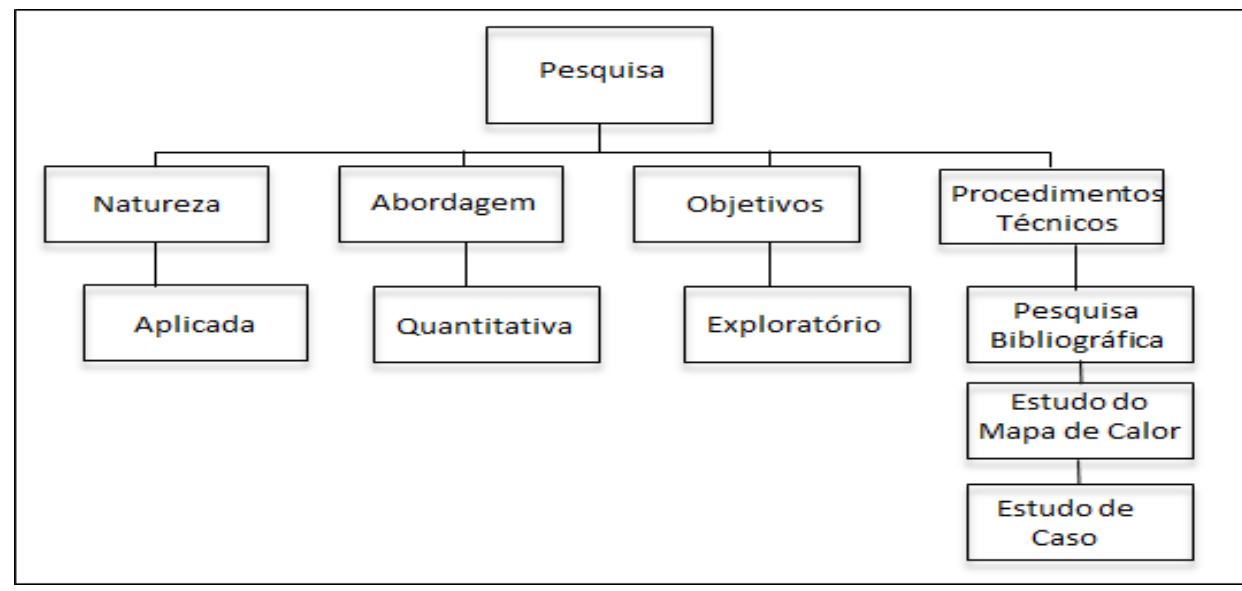

Figura 1. Proposta Metodológica. Fonte: adaptada de SANTOS, MARINS (2010)

Para a comparação das variáveis e obtenção das informações para as análises necessárias, optou-se por utilizar a ferramenta Mapa de Calor, que é considerada uma das melhores ferramentas de visualização de dados de densidade de pontos, assim como, o método mais indicado para identificar aglomerados e encontrar onde existe uma elevada concentração de determinada atividade (OLIVEIRA, CARDOSO, NASCIMENTO, 2017).

\section{ABRANGÊNCIA DA EXPORTAÇÃO DE SERVIÇOS}

Este capítulo discorrerá sobre o comportamento do mercado de exportação de serviços, inicialmente mundial, em seguida do Brasil e então da Região Metropolitana do Vale do Paraíba, contextualizando a abrangência do tema em comento.

\subsection{Momento Histórico}

Década de 1990 - A Rodada Uruguai e o Acordo Geral sobre Tarifas e Comércio (GATT), de 1993, reduziram as barreiras para o comércio internacional de serviços. Apesar das melhores condições de livre comércio, ainda há a crença entre os profissionais das empresas de serviços de que é difícil operar fora dos mercados internos devido à falta de recursos, pouco conhecimento sobre exportação e a crença de que as diferenças linguísticas e culturais tornarão a internacionalização muito exigente (GRÖNROOS, 1999).

A partir dos anos 2000 o comércio exterior de serviços adquire cada vez mais importância para empresas que buscam expandir seus mercados e, também, para a economia do Brasil como um todo, que se fortalece mediante o ingresso de divisas, a geração de emprego e renda e a aquisição e o desenvolvimento de expertise e tecnologia. Diversos fatores são determinantes na decisão de exportar serviços ou de internacionalizar uma empresa. Esses fatores são, ao mesmo tempo, desafios e oportunidades para a consolidação da competitividade de uma empresa. São exemplos, isolados ou em conjunto: diversificação de mercados; redução da dependência com relação ao mercado interno; promoção da imagem da empresa; aumento da produtividade; melhoria da qualidade, entre outros. Contudo, deve-se observar se a empresa tem vocação e condição para exportar, e a exportação não deve ser uma alternativa para quando a economia no próprio país está ruim, ela deve fazer parte de uma estratégia da empresa, que envolve preparo e planejamento (MDIC, 2017).

\subsection{Panorama Mundial, Brasileiro e da RM Vale}

As exportações mundiais de serviços alcançaram US\$ 4,9 trilhões em 2016, um terço do valor das exportações de mercadorias. O comércio global de serviços permaneceu estagnado por dois anos, após um período de crescimento constante de 2009 a 2014. As exportações de serviços ocorrem 
principalmente em economias desenvolvidas, que juntas representaram dois terços das exportações totais de serviços. O líder do mercado de exportação de serviços em 2016 foram os Estados Unidos da América, com US\$752 bilhões em serviços vendidos internacionalmente, representando 15\% das exportações mundiais. Entre as economias em desenvolvimento, os principais atores do mercado de exportação de serviços estão localizados na Ásia, liderado pela China (US\$ 208 bilhões) e pela Índia (US\$ 162 bilhões). O Brasil é o $32^{\circ}$ colocado mundialmente, porém, o mais atuante na América do Sul, fechando 2016 com US\$ 33,3 bilhões em exportação de serviços, de um total de US\$ 78,9 de todos os participantes neste mercado, do continente Sul Americano, conforme mostra a Figura 2 (UNCTAD, 2017).

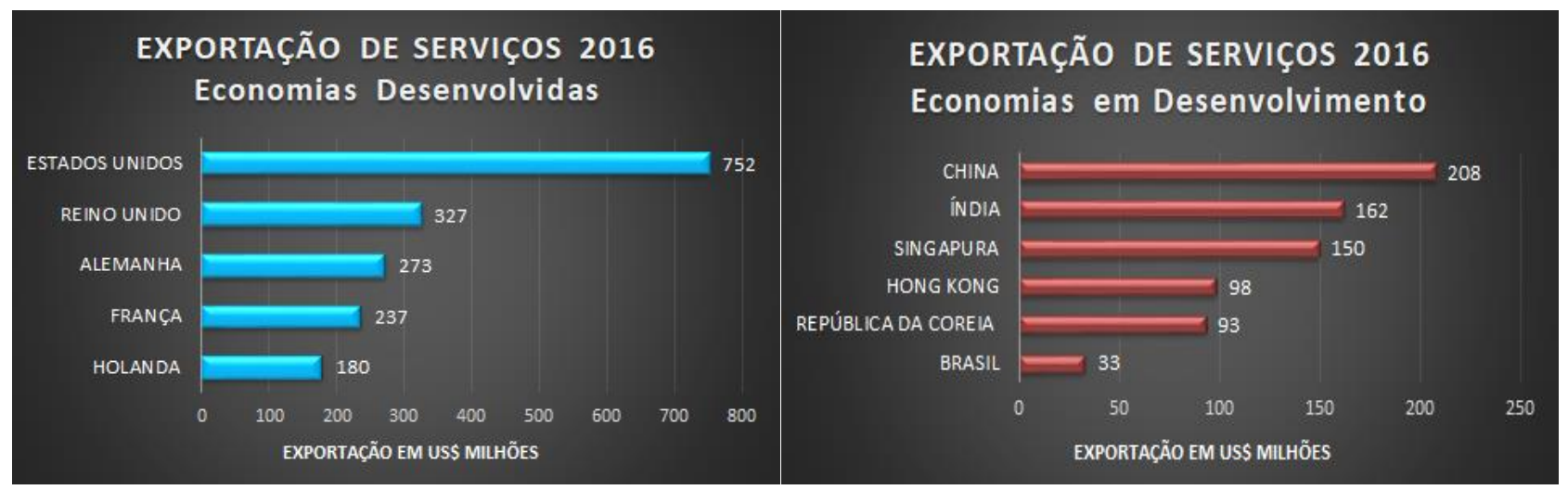

Figura 2. Exportação de serviços 2016 - Fonte: Autores, adaptado de UNCTAD (2017)

No Brasil As Regiões Sul e Sudeste, consideradas em conjunto, representam 96,7\% das exportações (sendo seus estados os 7 primeiros colocados entre os principais exportadores de serviços intangíveis brasileiros) e $96 \%$ das importações de serviços registradas no SISCOSERV no ano de 2016. São Paulo e Rio de Janeiro são os estados que apresentam destaque no desempenho nas exportações e nas importações. Em 2016, São Paulo, exportou o equivalente a US\$ 8,7 bilhões, foi o principal estado brasileiro exportador de serviços representando $62,2 \%$ do total das exportações. $\mathrm{O}$ principal item da pauta exportadora foram os "serviços profissionais, técnicos e gerenciais" (12,5\% do total exportado pelo estado), mantendo a posição em relação a 2015. O Vale do Paraíba, considerando as cidades de Caçapava, Jacareí, Pindamonhangaba, Guaratinguetá, São José dos Campos, Taubaté e Tremembé, vide Figura 3, somam cerca de US\$ 800 milhões em exportação de serviços, distribuídos entre aproximadamente 232 empresas exportadoras. (MDIC, 2016).

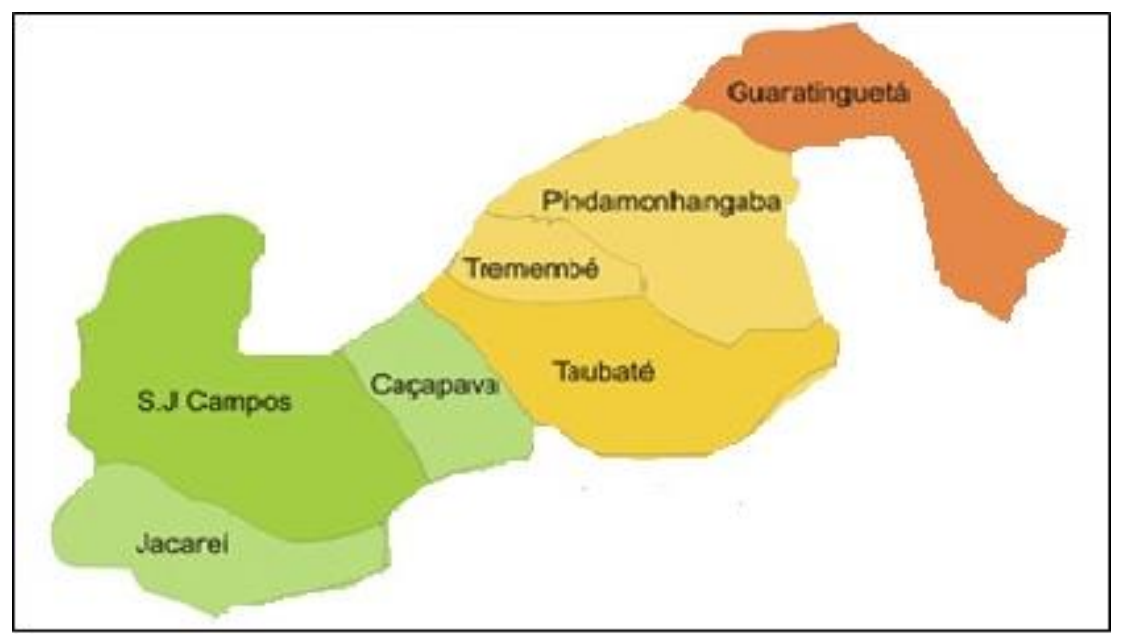

Figura 3. Cidades Exportadoras de Serviços. Fonte: os Autores, adaptado de EMPLASA (2016) 
Um país com a grandeza e o potencial do Brasil não pode se contentar em ter uma participação menor do que $1 \%$ do comércio internacional de serviços. O desafio não é somente o de exportar mais e sim o de internacionalizar as empresas, ou seja, prepará-las para competir no mercado internacional (SEBRAE, 2015)

\section{METODOLOGIA - MAPA DE CALOR}

Desenvolvido nos anos 1990 por Cormac Kinney, empreendedor e software designer, o mapa de calor (heatmap) é uma ferramenta que representa, por meio de cores, concentrações de determinado segmento em determinada região ou área. Neste trabalho essa ferramenta será utilizada para mostrar onde estão concentradas as empresas exportadoras de serviço no Vale do Paraíba, com isso será possível avaliar o que levou a essa concentração em uma cidade e não em outra. Além disso, o resultado da avaliação do mapa de calor e do conjunto de dados por ele mostrados, pode ser uma importante ferramenta para a tomada de decisão, por exemplo, para a instalação de futuras empresas exportadoras ou a transformação de empresas de perfil doméstico para perfil internacional. A Figura 4 a seguir, traz um exemplo genérico de um mapa de calor.

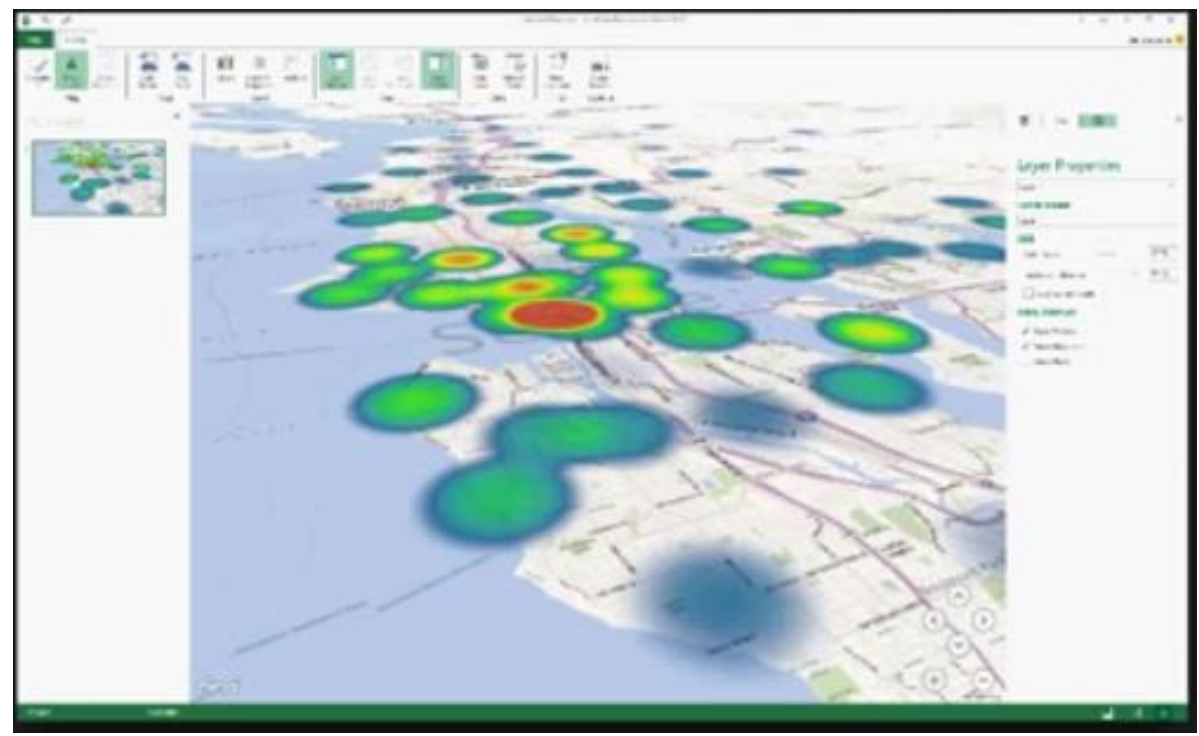

Figura 4. Exemplo de Mapa de Calor. Fonte: EXCEL (2018) do Excel.

O Mapa de Calor utilizado neste trabalho foi desenvolvido por meio da ferramenta Power Map

\section{APLICAÇÃO DO MAPA DE CALOR}

Esse capítulo apresenta a utilização da base de dados da movimentação das empresas exportadoras de serviços, presentes no Vale do Paraíba, no ano de 2016, utilizando o mapa de calor para identificar áreas de concentração dessas empresas. Após a aplicação do mapa é feita uma análise dos dados e identificação dos possíveis motivos que levaram a essa concentração.

\subsection{Levantamento dos dados}

O Mapa de calor da Figura 5, representa a concentração de empresas na cidade de São José dos Campos (115), seguida por Taubaté (33), Jacareí (32), Pindamonhangaba (20), Caçapava (19), Guaratinguetá (11), e Tremembé (2). 


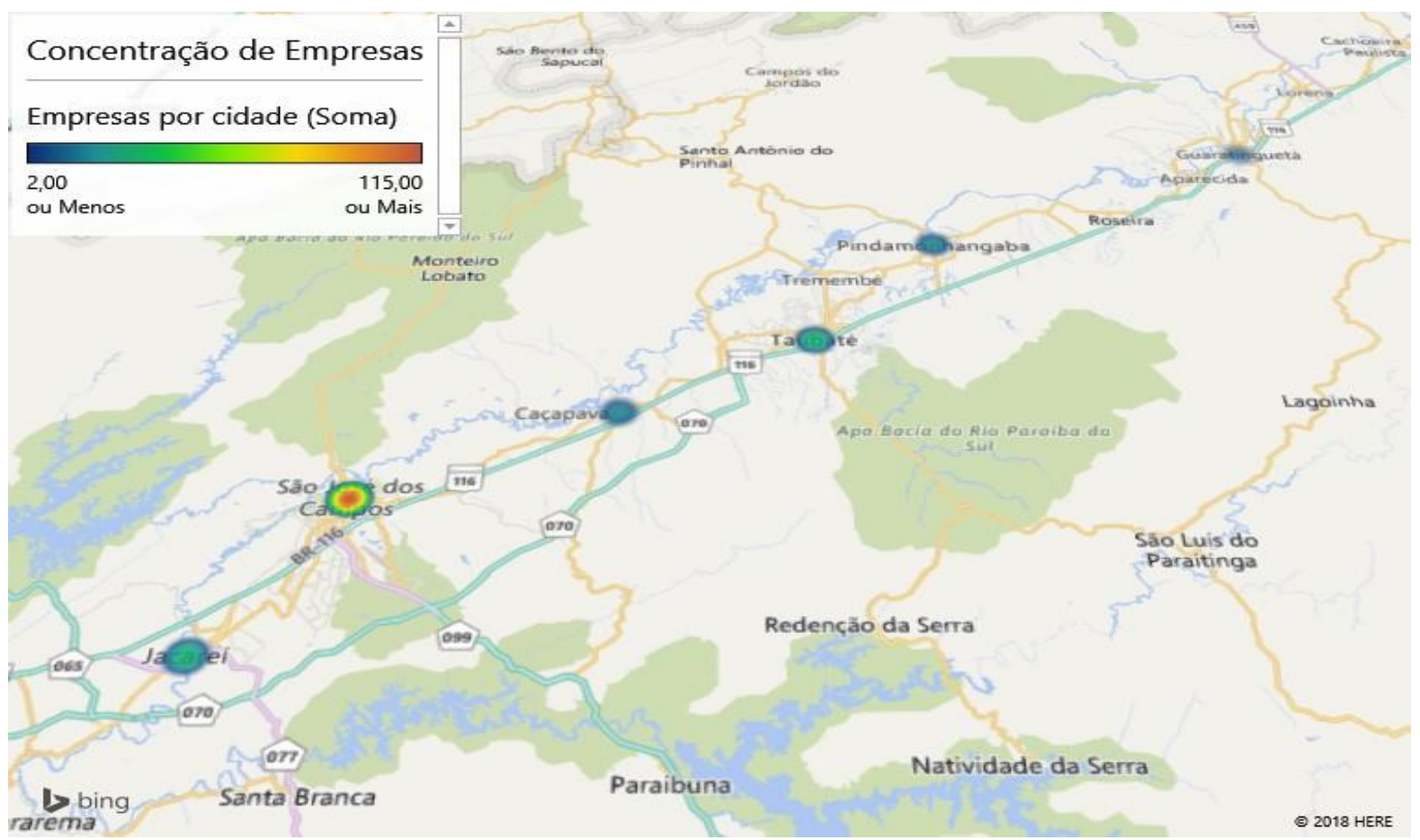

Figura 5. Concentração de Empresas por Cidade. Fonte: EXCEL (2018)

O Mapa de calor da Figura 6, representa a concentração de volume de exportação por cidade em US\$ milhões. A cidade de São José dos Campos também é a líder nesse quesito (465), seguida por Pindamonhangaba (137), Taubaté (692), Jacareí (59), Caçapava (56), Guaratinguetá (20), e Tremembé (2).

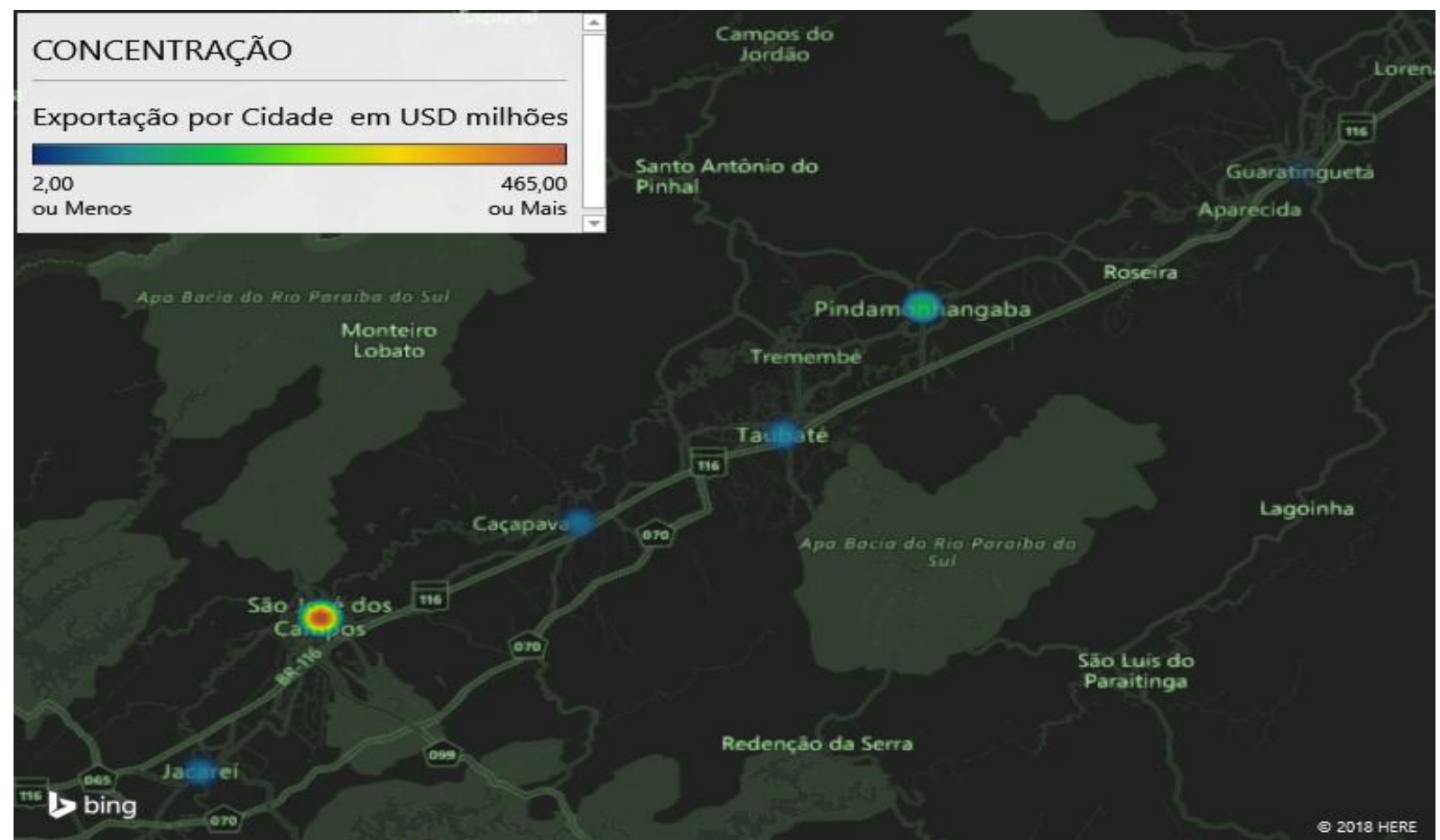

Figura 6. Valor exportado por cidade em US\$ Milhões. Fonte: EXCEL (2018) 


\subsection{Análise dos dados}

Com o objetivo de avaliar os resultados obtidos com a aplicação da ferramenta Mapa de Calor, observa-se que a cidade de São José dos Campos concentra tanto a maior quantidade de empresas exportadoras do Vale do Paraíba (49,6\%), quanto o maior valor de exportação de serviços $(57,5 \%)$. Os Gráfico 1 e 2, a seguir, mostram as porcentagens da concentração das empresas por cidade e os valores negociados.

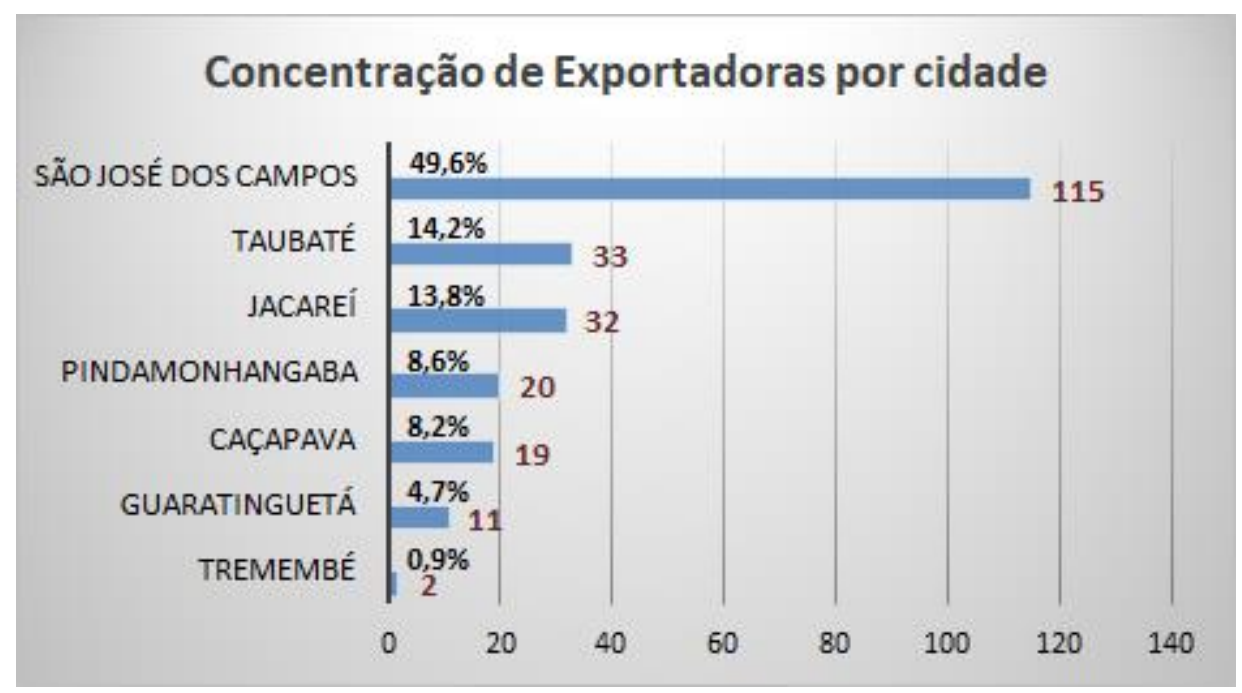

Gráfico 1. Concentração de Empresas Exportadoras por Cidade. Fonte: Autores

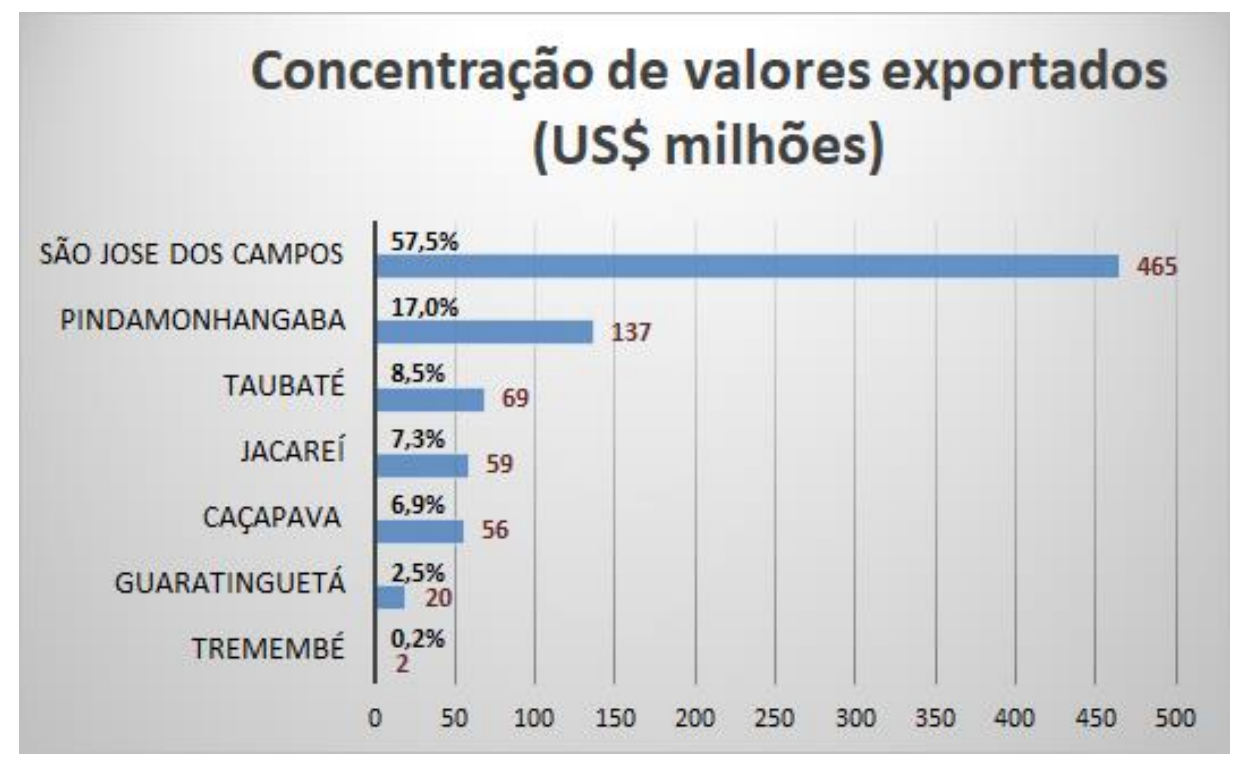

Gráfico 2. Concentração de Valores Exportados - Fonte: autores

\subsection{Uma Empresa Exportadora}

De acordo com o resultado obtido com a utilização da ferramenta mapa de calor, a cidade São José dos Campos concentra o maior número de empresas exportadoras da RM Vale. Com o objetivo de identificar os possíveis motivos que levaram a essa concentração, escolheu-se uma empresa desta cidade, para o levantamento de informações. Uma entrevista foi conduzida por e-mail à Export Service, uma empresa que atua com engenharia, consultoria e projetos aeronáuticos, localizada no Parque Tecnológico de São José dos Campos. Foi perguntado o que levou os sócios a abrirem a 
empresa em SJC - benefícios fiscais; localização geográfica ou proximidade a indústrias específicas. A empresa declarou não usufruir de benefícios fiscais e esse fator não interferiu na escolha da cidade. Essa escolha se deu pelos seguintes fatores: disponibilidade de mão de obra qualificada na região, oportunidade de instalação de uma incubadora e posteriormente oportunidade de instalação no Parque Tecnológico de São José dos Campos. A instalação no Parque Tecnológico refletiu benefícios mais amplos do que incentivos fiscais representariam. Além disso, sua localização facilita o acesso à Secretaria Municipal de Inovação e Desenvolvimento Econômico, além de propiciar contatos com empresas inovadoras e profissionais de tecnologia de vários setores. Outro fato que contou foi a proximidade com a indústria Aeronáutica, já que o negócio da empresa é essencialmente de engenharia e projetos aeronáuticos.

A empresa também informou que foi feita uma consulta à Prefeitura de São José dos Campos para a redução da tarifa de ISS, de $3 \%$ para $2 \%$ - isso é possível para determinados segmentos porém, para a Export Service não foi possível, naquele momento, devido a alguns detalhes de natureza técnica. Tal benefício representaria uma melhoria significativa no faturamento da empresa considerando a parte dos serviços desenvolvidos no Brasil, já que na exportação, ou seja, para serviços prestados no exterior, não há incidência de ISS.

O faturamento da Export Service em 2016 foi o equivalente a US\$349,500.00 com as exportações de serviços representando $36 \%$ desse faturamento. Analisando o total exportado por São José dos Campos no mesmo ano, USD 465,000,000.00 conclui-se que a empresa participou de 0,3\% do total de exportações da cidade.

\subsection{Tabela Comparativa da alíquota de ISS}

A alíquota de recolhimento do imposto sobre serviços (ISS), varia de acordo com a cidade em questão. Apesar de não ser o único fator nem o mais importante, a alíquota de ISS pode impactar no momento da opção pela abertura de uma empresa em uma determinada cidade. Como forma de comparar as alíquotas de ISS das cidades exportadoras de serviço do Vale do Paraíba, montou-se a Tabela 1, fazendo uso da classificação 7.01 - abrange os serviços executados pela empresa Export Service.

Tabela1: Alíquota de ISS

\begin{tabular}{|c|c|}
\hline \multicolumn{2}{|c|}{$\begin{array}{l}7.01 \text { - Serviços de engenharia, agronomia, agrimensura, } \\
\text { arquitetura, geologia, urbanismo, paisagismo e congêneres. }\end{array}$} \\
\hline CIDADE & ALIQUOTA \\
\hline Tremembé & $3 \%$ \\
\hline Caçapava & $5 \%$ \\
\hline Guaratinguetá & $3 \%$ \\
\hline Pindamonhangaba & $2 \%$ \\
\hline Jacareí & $3 \%$ \\
\hline Taubaté & $5 \%$ \\
\hline São José dos Campos & $3 \%$ \\
\hline
\end{tabular}

Fonte: Autores (2018)

Baseado no exemplo da Tabela 1 e ponderando com o que mostra os Gráficos 1 e 2, pode-se notar que Pindamonhangaba é a cidade que possui a menor alíquota de ISS (2\%), e significativa participação em volume exportado (segunda posição com 17\%). Em contrapartida Taubaté, que 
possui uma das maiores alíquotas de ISS (5\%), ocupa o segundo lugar no quesito concentração de empresas exportadoras (14,2\%), perdendo apenas para a líder São José dos Campos (49,6\%), cuja alíquota de ISS apresenta-se na média (3\%).

\section{CONCLUSÃO}

Em um mundo cada vez mais competitivo, as empresas precisam estar em constante evolução e inovação para que possam crescer ou simplesmente permanecer no mercado. Principalmente quando o mercado nacional atravessa crise, mas não apenas em decorrência disso, a possibilidade de incursão em mercados externos pode ser a solução para crescimento e a fuga da estagnação. Para algumas empresas, a perspectiva de entrar no mercado internacional pode ser assustadora devido ao desconhecimento do terreno e às diferenças culturais, de idioma e moeda. Por este motivo faz-se necessário se preparar, treinar a equipe, garantir a qualidade dos serviços prestados, agir com seriedade e essencialmente planejar absolutamente tudo. No Brasil há várias organizações, governamentais ou não governamentais, que servem de apoio e direcionamento para aquelas empresas interessadas em tornarem-se exportadores de serviços. Esse mercado tem muito a crescer no nosso país. Em 2016 o Brasil participava com menos de 1\% do total das exportações de serviços mundial, mas o país tem capacidade para ir muito além disso, pela diversidade de serviços exportáveis e qualidade da mão de obra, entre outros fatores. A pesquisa realizada por esse trabalho apontou que o Vale do Paraíba tem grande potencial para crescimento. As 7 cidades identificadas somam 232 empresas exportadoras, nota-se que o volume de serviço exportado por essas empresas ainda é muito baixo, principalmente levando-se em conta que na região estão empresas do setor aeronáutico, automobilístico e de ciência e tecnologia, setores cujos serviços relacionados são de alto valor agregado. $\mathrm{O}$ resultado não é conclusivo quando se avalia os prováveis motivos para a concentração de empresas exportadoras na cidade de São José dos Campos, porém, com base no depoimento da empresa entrevistada (Export Service), pode-se citar que o que contribuiu para a sua instalação nesta cidade foi a disponibilidade de mão de obra qualificada, as características do Parque Tecnológico de São José dos Campos que viabiliza várias oportunidades de contatos e negócios, além da presença na cidade de várias empresas do setor aeronáutico. Analisando a cidade de Pindamonhangaba que participa com $17 \%$ do volume exportado ( $2^{\circ}$. Lugar) e a menor alíquota de ISS (2\%), pode-se presumir que para as 20 empresas lá instaladas, a alíquota de ISS é relevante. Em determinadas situações a isenção de ISS ou uma alíquota reduzida pode contribuir para a tomada de decisão na abertura de uma empresa em uma terminada cidade. Mas quando se trata de serviço exportado, esse quesito não é impactante, já que não há incidência desse imposto para serviços desenvolvidos no exterior.

\section{REFERÊNCIAS}

BCB, Banco Central do Brasil, 2016. Indicadores Econômicos. Disponível em https://www.bcb.gov.br/pec/Indeco/Port/indeco.asp. Acesso em: 25/03/2018.

GRÖNROOS, C. Internationalization Strategies for Services, Journal of Services Marketing, Vol. 13 Issue: 4/5, pp.290-297, MCB UP Limited, 1999. Disponível em: https://doi.org/10.1108/08876049910282547. Acesso em: 28/03/2018.

EMPLASA, Empresa Paulista de Planejamento Metropolitano, São Paulo, 2016. Região Metropolitana do Vale do Paraíba e Litoral Norte. Disponível em: https://www.emplasa.sp.gov.br/RMVPLN. Acesso em 11/06/2018. 
EXCEL, Microsoft Office. Introdução ao Power Map. Disponível em: https://support.office.com/pt-br/article/introdu\%C3\%A7\%C3\%A3o-ao-power-map-88a28df6-825840aa-b5cc-577873fb0f4a. Acesso em: 11/06/2018.

MDIC, Ministério da Indústria, Comércio Exterior e Serviços. Estatísticas do comércio exterior de serviços, 2016. Panorama do Comércio Internacional. Disponível em: http://www.mdic.gov.br/images/REPOSITORIO/scs/decin/Estat\%C3\%ADsticas_de_Com\%C3\%A 9rcio_Exterior/2016/Panorama_Oficial_2016_Final_.pdf. Acesso em: 25/03/2018;

MDIC, Ministério da Indústria, Comércio Exterior e Serviços. Estatísticas do Comércio Exterior de Serviços - 2016. Empresas Brasileiras Vendedoras e Adquirentes de Serviços Intangíveis. Disponível em http://www.mdic.gov.br/index.php/comercio-servicos/estatisticas-do-comercioexterior-de-servicos/2555-estatisticas-do-comercio-exterior-de-servicos-2016;

MDIC, Ministério da Indústria, Comércio Exterior e Serviços. Guia básico para exportação de serviços, 2017. Disponível em http://www.mdic.gov.br/images/REPOSITORIO/scs/decin/Guia_B\%C3\%A1sico/Guia_B\%C3\%A1 sico_-_versao_2017.pdf. Acesso em 15/04/2018;

OLIVEIRA, K. S. P. L.; CARDOSO, M. H.; NASCIMENTO, M.V. Concentração espacial de empresas transportadoras de carga: aplicação para a região do vale do paraíba paulista no eixo da Rodovia Presidente Dutra. In: IV CIMATech - CONGRESS OF INDUSTRIAL MANAGEMENT AND AERONAUTICAL TECHNOLOGY, 2017, São José dos Campos. Anais...São José dos Campos;

SANTOS, R.F.; MARINS, F.A.S.; Modelo Integrado de Gerenciamento da Logística Reversa para a disposição dos produtos eletrônicos e seus componentes sob a ótica da PNRS. Cap 3, $1^{a}$. Edição. Poisson, 2018;

SEBRAE, Serviço Brasileiro de Apoio às Micro e Pequenas Empresas. Exportações de Serviços Brasileiros. 2015. Disponível em http://www.sebrae.com.br/sites/PortalSebrae/bis/exportacoes-deservicos-brasileiros,d41c26ad18353410VgnVCM1000003b74010aRCRD. Acesso em: 21/05/2018.

SEBRAE, Serviço Brasileiro de Apoio às Micro e Pequenas Empresas. Como exportar serviços características e desafios, 2016. Disponível em: http://www.sebrae.com.br/sites/PortalSebrae/bis/como-exportar-servicos-caracteristicas-edesafios,e14836627a963410VgnVCM1000003b74010aRCRD. Acesso em: 25/03/2018;

UNCTAD, United Nations Conference on Trade and Development. Handbook Statistcs, 2017. Disponível em http://stats.unctad.org/handbook/Services/Total.html. Acesso em: 21 05/2018;

\section{INFORMAÇÕES ADICIONAIS}

Este Trabalho e todos os conceitos nele emitidos são de responsabilidade dos autores. 